\title{
PENGARUH TERAPI OKUPASI DENGAN TEKNIK KOLASE TERHADAP PERKEMBANGAN MOTORIK HALUS ANAK AUTIS DI TERAPI ANAK MANDIRI CENTER SETIABUDI MEDAN TAHUN 2015
}

\author{
Tiurlan Mariasima Doloksaribu, Martianus Giawa \\ Jurusan Keperawatan Poltekkes Medan
}

\begin{abstract}
Abstrak
Autis diartikan sebagai anak yang suka menyendiri / asyik dengan dunianya sendiri. Gangguan yang dialami anak autis adalah keterlambatan dalam perkembangan motorik halus. Tujuan penelitian ini adalah menganalisis Pengaruh Terapi Okupasi Dengan Teknik Kolase Terhadap Perkembangan Motorik Halus Pada Anak Autis di Terapi Anak Mandiri Center Setiabudi Medan. Terapi okupasi merupakan upaya penyembuhan terhadap anak yang memiliki kelainan fisik dan mental dengan cara memberikan keaktifan kerja. sebuah teknik menempel berbagai macam unsur kedalam satu frame sehingga menghasilkan karya seni yang baru. Jenis Penelitian ini adalah analitik dengan desain Quasy Experimental dengan menggunakan metode pre test-post test one group design dengan metode pengambilan sampel adalah sampling jenuh/total sampling, jumlah sampel dalam penelitian ini adalah 11 anak. Hasil penelitian dan Hasil Uji pada taraf kepercayaan 95\% didapatkan bahwa adanya pengaruh terapi okupasi dengan teknik kolase terhadap rerata perkembangan motorik halus pada 11 anak autis dalam memberi lem pada gambar ( $\mathrm{P}$ value $=0,000$ ), mengambil bijian $(\mathrm{P}$ value $=0,006)$, menempel bijian $(\mathrm{P}$ value $=0,002)$ dan keberhasilan dalam mengisi gambar ( $\mathrm{P}$ value $=0,004)$. Disarankan kepada terapis untuk menerapkan terapi okupasi dengan teknik kolase dengan menggunakan benda-benda yang bervariasi untuk pengembangan kemampuan motorik halus anak berkebutuhan khusus terutama anak autis.
\end{abstract}

Kata kunci : Autis, Motorik Halus, Terapi Okupasi, Teknik Kolase

\section{PENDAHULUAN}

Autis diartikan sebagai anak yang suka menyendiri / asyik dengan dunianya sendiri (Hasdianah, 2013). Klasifikasi anak autis menurut Mangunsong (2009), antara lain : Autisme infantil atau autisme masa kanakkanak, Asperger Syndrome (AS), Rett Syndrome, Childhood Disintegrative Disorder, Pervasive Developmental not Otherwise Specified (PDD-NOS), High Fungtion Autism.

United Nations Educational, Scientific, and Cultural Organization (UNESCO) pada 2011 mencatat, sekitar 35 juta orang penyandang autis di dunia, yang berarti rata-rata 6 dari 1000 orang di dunia mengidap autis. Centers for Disease Control and Prevention (CDC) 2002 mencatat di Amerika Serikat, penderita autis sebanyak 60 : 10.000 kelahiran, tahun 2008 perbandingan autis pada anak usia 8 tahun yang terdiangnosa autis adalah 1: 80, tahun 2013 sebanyak 1:50 kelahiran.

Data Departemen Kesehatan tahun 2004 mencatat terdapat 7000 penderita autis di Indonesia. Badan Pusat Statistik (2010) diperkirakan penderita autis mencapai 2,4 juta orang dengan jumlah penduduk Indonesia mencapai 237,5 juta dan laju pertumbuhan penduduk sebanyak 1,14 \%. Data Departemen Kesehatan 2013, prevalensi autis di Indonesia diperkirakan mencapai 112.000 jiwa.
Gangguan yang dialami anak autis adalah keterlambatan dalam perkembangan motorik halus. Gerakgeriknya kaku dan kasar, mereka kesulitan untuk memegang pensil dengan cara yang benar, kesulitan untuk memegang sendok dan menyuap makanan kedalam mulutnya, dan lain sebagainya (Hasdianah, 2013). Anak autis memiliki permasalahan pada aspek motorik halusnya (Sujarwanto, 2005). Motorik halus adalah gerakan yang hanya melibatkan bagian-bagian tubuh tertentu yang dilakukan oleh otot-otot kecil saja (Departemen Pendidikan Nasional, 2007). Melatih motorik halus salah satunya melalui terapi okupasi dengan teknik kolase, dengan cara anak dilatih menggunakan kemampuan gerak otot-otot kecilnya sehingga bisa dikembangkan secara optimal, yaitu dengan memegang, mengambil, menjempit, menggenggam, serta menempel (Kumalasari, 2005).

Terapi Okupasi adalah bentuk pelayanan kesehatan kepada klien dengan kecacatan fisik dan mental yang mempunyai gangguan pada kinerja okupasional, dengan menggunakan aktivitas bermakna (okupasi) untuk mengoptimalkan kemandirian individu pada area aktivitas kehidupan sehari-hari, produktivitas dan pemanfaatan waktu luang (Peraturan Menteri Kesehatan No.7 Tentang Standar Pelayanan Terapi Okupasi, 2014). Kolase merupakan salah satu ragam latihan terapi okupasi. Muharrar dan Verayanti (2013) menjelaskan kolase adalah sebuah teknik menempel berbagai macam unsur kedalam 
satu frame sehingga menghasilkan karya seni yang baru Sukardi (2008), mengartikan kolase merupakan karya seni rupa dua dimensi yang menggunakan bahan yang bermacam-macam selama bahan dasar tersebut dapat dipadukan dengan bahan dasar lain yang akhirnya dapat menyatu menjadi karya yang utuh, sehingga dapat dikatakan bahwa bahan apapun yang dapat dikolaborasikan sehingga menjadi karya seni rupa dua dimensi dapat dijadikan bahan kolase.

Tujuan terapi okupasi adalah mengembalikan fungsi fisik serta motorik baik motorik halus maupun motorik kasar, mental, sosial, dan emosi dengan mengembangkan seoptimal mungkin serta memelihara fungsi yang masih baik dan mengarahkannya sesuai dengan keadaan individu agar dapat hidup yang layak di masyarakat. Sedangkan kegunaan kolase secara umum adalah untuk melatih kemampuan motorik halus anak, melatih memecahkan masalah, meningkatkan kreativitas, serta pengenalan bentuk dan warna ( Nurjatmika, 2012).

Fitriana, Eni dan W Widajati ( 2014) yang meneliti tentang Pengaruh Terapi Okupasi dengan Teknik Kolase Terhadap Kemampuan Motorik Halus Anak Autis di SLB PGRI Plosoklaten Kediri yang didapatkan sebelum dilakukan terapi okupasi dengan teknik kolase pada 6 anak autis di SLB PGRI Plosoklaten Kediri rerata kemampuan mereka sebesar 42,67 dan setelah dilakukan terapi rerata kemampuan mereka sebesar 68,25. Dari data tersebut didapatkan bahwa ada peningkatan perkembangan kemampuan motorik halus 6 anak autis sebesar 25,58.

Survei pendahuluan oleh peneliti tanggal 5 Februari 2015 di Terapi Anak Mandiri Center Setiabudi Medan, sebanyak 5 orang penderita autis mendapat terapi tahun 2013, tahun 2014 sebanyak 13 orang dan tahun 2015 sebanyak 17 penderita autis.`Berdasarkan hasil paparan diatas sehingga penulis tertarik untuk melakukan Penelitian Tentang Pengaruh Terapi Okupasi dengan Teknik Kolase Terhadap Perkembangan Motorik Halus Anak Autis di Terapi Anak Mandiri Center Setiabudi Medan.

\section{METODE PENELITIAN}

Desain dalam penelitian ini adalah Quasy Experimental dengan menggunakan metode pre test-post test one group design. Penelitian dilakukan dengan cara melakukan pre test (pengamatan awal) sebelum diberikan intervensi, dilanjutkan dengan pemberian intervensi kemudian dilakukan kembali post test yang bertujuan untuk mengetahui Pengaruh Terapi Okupasi Dengan Teknik Kolase Terhadap Perkembangan Motorik Halus Pada Anak Autis di Terapi Anak Mandiri Center Setiabudi Medan.

Populasi penelitian ini adalah seluruh anakanak yang sedang menjalani terapi pada Juli-Agustus 2015 di Terapi Anak Mandiri Center Setiabudi Medan berjumlah 11 anak. Tehnik pengambilan sampel adalah sampling jenuh/total sampling, yaitu mengambil semua anggota populasi menjadi sampel. Jenis pengumpulan data adalah jenis data primer. Data primer adalah data yang diperoleh oleh peneliti secara langsung dengan cara atau melalui pengisian lembar observasi dan lembar instrumen.
Data sekunder, data yang dikumpulkan dari berbagai sumber yang dijadikan sebagai sumber data, tentang data jumlah anak-anak yang diperoleh dari Terapi Anak Mandiri Center Setiabudi Medan 2015. Peneliti menjelaskan tujuan penelitian, Peneliti mewawancarai kepala terapis okupasi yang ada di Terapi Anak Mandiri Center Setiabudi Medan untuk mendapatkan data jumlah anak autis yang sedang menjalani terapi serta kemampuan anak autis, khususnya kemampuan motorik halus, memberikan surat persetujuan menjadi responden, melakukan pre test yaitu mengamati anak autis yang sedang di terapi oleh okupasi terapis dalam melakukan teknik kolase dengan tahapan, Pertama : menjaga kenyamanan dan privacy anak. Kedua, memberikan intervensi dengan menyuruh anak mengoyak kertas yang berwarna (origami) dan menempel pada gambar yang telah ditentukan selama 15-20 menit. Tahap ketiga, tahap evaluasi dimana peneliti mengobservasi hasil yang telah dilakukan oleh anak dalam hal menempel kertas berwarna ke dalam gambar yang telah ditentukan. Mengajarkan teknik kolase dan melakukan post tes.

\section{HASIL PENELITIAN}

Responden sebanyak 11 orang anak autis yang sedang menjalani terapi di Terapi Anak Mandiri Center Setiabudi Medan

Tabel 1. Distribusi Frekuensi Anak Autis berdasarkan umur di Terapi Anak Mandiri Center Setiabudi Medan tahun 2015

\begin{tabular}{ccc}
\hline Umur & Frekuensi & $\%$ \\
\hline 3 tahun & 2 & 18,2 \\
4 tahun & 2 & 18,2 \\
5 tahun & 4 & 36,4 \\
6 tahun & 3 & 27,3 \\
\hline Total & 11 & 100,0 \\
\hline
\end{tabular}

Dari 11 responden, mayoritas responden berusia 5 tahun sebanyak 4 anak dengan persentase $36,4 \%$.

Tabel 2. Distribusi Frekuensi Anak Autis berdasarkan Jenis Kelamin di Terapi Anak Mandiri Center Setiabudi Medan Tahun 2015

\begin{tabular}{ccc}
\hline Jenis Kelamin & Frekuensi & \% \\
\hline laki-laki & 9 & 81,8 \\
perempuan & 2 & 18,2 \\
\hline Total & 11 & 100,0 \\
\hline
\end{tabular}

Dari 11 responden, mayoritas responden berjenis kelamin laki-laki sebanyak 9 anak dengan persentase $81,8 \%$. 
Tabel 3. Distribusi Frekuensi Kemampuan Motorik Halus dalam hal Memberi Lem pada Gambar Sebelum dilakukan Terapi Okupasi Pada Anak Autis di Terapi Anak Mandiri Center Setiabudi Medan Tahun 2015

\begin{tabular}{ccccc}
\hline $\begin{array}{c}\text { Kategori } \\
\text { Kemampuan }\end{array}$ & F Pre & $\%$ & $\begin{array}{c}\text { F } \\
\text { Post }\end{array}$ & $\%$ \\
\hline $\begin{array}{l}\text { Dapat memberi } \\
\text { lem pada gambar } \\
\text { tanpa bantuan }\end{array}$ & 1 & 9,1 & 7 & 63,6 \\
$\begin{array}{l}\text { Dapat memberi } \\
\text { lem pada gambar } \\
\text { dengan bantuan }\end{array}$ & 7 & 63,6 & 4 & 36,4 \\
$\begin{array}{l}\text { Tidak dapat } \\
\text { memberi lem pda } \\
\text { gambar }\end{array}$ & 3 & 27,3 & 0 & 0 \\
\hline Total & 11 & 100,0 & 11 & 100,0 \\
\hline
\end{tabular}

Sebelum dilakukan terapi okupasi dengan teknik kolase mayoritas anak autis dapat memberi lem pada gambar dengan bantuan sebanyak 7 anak $(63,6 \%)$ dan setelah dilakukan terapi okupasi dengan teknik kolase mayoritas anak autis dapat memberi lem pada gambar tanpa bantuan sebanyak 7 anak $(63,6 \%)$.

Tabel 4. Distribusi Frekuensi Kemampuan Motorik Halus dalam hal Mengambil Bijian Sebelum dan Sesudah dilakukan Terapi Okupasi Pada Anak Autis di Terapi Anak Mandiri Center Setiabudi Medan Tahun 2015.

\begin{tabular}{|c|c|c|c|c|}
\hline $\begin{array}{c}\text { Kategori } \\
\text { kemampuan }\end{array}$ & F Pre & $\%$ & $\begin{array}{c}\mathrm{F} \\
\text { Post }\end{array}$ & $\%$ \\
\hline $\begin{array}{l}\text { Dapat } \\
\text { mengambil } \\
\text { bijian tanpa } \\
\text { bantuan }\end{array}$ & 4 & 36,4 & 10 & 90,9 \\
\hline $\begin{array}{l}\text { Dapat } \\
\text { mengambil } \\
\text { bijian dengan } \\
\text { bantuan }\end{array}$ & 7 & 63,6 & 1 & 9,1 \\
\hline Total & 11 & 100,0 & 11 & 100,0 \\
\hline
\end{tabular}

Sebelum dilakukan terapi okupasi dengan teknik kolase, mayoritas anak autis dapat mengambil bijian dengan bantuan sebanyak 7 anak $(63,6 \%)$ dan setelah dilakukan terapi okupasi dengan teknik kolase, mayoritas anak autis dapat mengambil bijian tanpa bantuan sebanyak 10 anak $(90,9 \%)$.
Tabel 5. Distribusi Frekuensi Kemampuan Motorik Halus dalam hal Menempel Bijian pada Gambar Sebelum dan sesudah dilakukanTerapi Okupasi Pada Anak Autis di Terapi Anak Mandiri Center Setiabudi Me danTahun 2015.

\begin{tabular}{|c|c|c|c|c|}
\hline $\begin{array}{c}\text { Kategori } \\
\text { Kemampuan }\end{array}$ & $\begin{array}{c}\mathrm{F} \\
\text { Pre }\end{array}$ & $\%$ & $\begin{array}{c}\text { F } \\
\text { Post }\end{array}$ & $\%$ \\
\hline $\begin{array}{lr}\text { Dapat } & \text { menempel } \\
\text { bijian } & \text { pada } \\
\text { gambar } & \text { tanpa } \\
\text { bantuan } & \end{array}$ & 1 & 9,1 & 8 & 72,7 \\
\hline $\begin{array}{lr}\text { Dapat } & \text { menempel } \\
\text { bijian } & \text { pada } \\
\text { gambar } & \text { dengan } \\
\text { bantuan } & \end{array}$ & 10 & 90,9 & 3 & 27,3 \\
\hline Total & 11 & 100,0 & 11 & 100,0 \\
\hline
\end{tabular}

Sebelum dilakukan terapi okupasi dengan teknik kolase, mayoritas anak autis dapat menempel bijian pada gambar dengan bantuan sebanyak 10 anak $(90,9)$ dan setelah dilakukan terapi okupasi dengan teknik kolase mayoritas anak autis dapat menempel bijian pada gambar tanpa bantuan sebanyak 8 anak $(72,7 \%)$.

Tabel 6. Distribusi Frekuensi Keberhasilan dalam mengisi Gambar Sebelum dan sesudah dilakukan Terapi Okupasi Pada Anak Autis di Terapi AnakMandiri Center Setiabudi Medan Tahun 2015.

\begin{tabular}{lcccc}
\hline $\begin{array}{c}\text { Kategori } \\
\text { Keberhasilan }\end{array}$ & F Pre & $\%$ & $\begin{array}{c}\text { F } \\
\text { Post }\end{array}$ & $\%$ \\
\hline $\begin{array}{l}\text { A (Sangat Baik) }= \\
80 \%-100 \%\end{array}$ & 0 & 0 & 2 & 18,2 \\
B (Baik) $=75 \%-$ & 2 & 18,2 & 2 & 18,2 \\
$79 \%$ & & & & \\
C ( Cukup) $=70 \%$ & 0 & 0 & 5 & 45,5 \\
$-74 \%$ & & & & \\
$\begin{array}{l}\text { D (Kurang) }=< \\
69 \%\end{array}$ & 9 & 81,8 & 2 & 18,2 \\
\hline Total & 11 & 100,0 & 11 & 100,0 \\
\hline
\end{tabular}

Sebelum dilakukan terapi okupasi dengan teknik kolase, mayoritas keberhasilan anak autis dalam mengisi gambar adalah kategori kurang sebanyak 9 anak $(81,1 \%)$ dan sesudah dilakukan terapi okupasi dengan teknik kolase, mayoritas keberhasilan anak autis dalam mengisi gambar adalah Cukup (70\%-74\% bagian gambar) sebanyak 5 anak $(45,5 \%)$. 
Tabel 7. Perbedaan Rerata Kemampuan Motorik Halus Anak Autis Dalam Memberi Lem Pada Gambar Sebelum dan Sesudah Diberikan Terapi Okupasi denganTeknik Kolase di Terapi Anak Mandiri Center Setiabudi Medan Tahun 2015

\begin{tabular}{lrccc}
\hline $\begin{array}{l}\text { Memberi } \\
\text { Gambar }\end{array}$ & Pada & Mean & SD & P Value \\
\hline $\begin{array}{l}\text { Sebelum } \\
\text { Okupasi }\end{array}$ & Terapi & & & \\
Teknik Kolase & dengan & 0,60 & 1,18 & \\
$\begin{array}{l}\text { Sesudah } \\
\text { Okupasi }\end{array}$ & Terapi & & & 0,000 \\
Teknik Kolase & dengan & 0,50 & 0,36 & \\
\hline
\end{tabular}

Terdapat perbedaan rata-rata memberi lem pada gambar antar individu yang bermakna antara sebelum dan sesudah diberikan intervensi ( $\mathrm{P}$ Value $<0,05)$. Sesudah dilakukannya intervensi terjadi peningkatan kemampuan motorik halus dalam memberi lem pada gambar sebesar 0,10 .

Tabel 8 Perbedaan Rerata Kemampuan Motorik Halus Anak Autis Dalam Mengambil Bijian Sebelum dan Sesudah Diberikan Terapi Okupasi denganTeknik Kolase di Terapi Anak Mandiri Center Setiabudi Medan Tahun 2015

\begin{tabular}{lrccc}
\hline \multicolumn{2}{l}{ Mengambil Bijian } & Mean & SD & $\begin{array}{c}\text { P } \\
\text { Value }\end{array}$ \\
\hline $\begin{array}{l}\text { Sebelum } \\
\text { Okupasi }\end{array}$ & $\begin{array}{c}\text { Terapi } \\
\text { dengan }\end{array}$ & 0,63 & 0,50 & \\
$\begin{array}{l}\text { Teknik Kolase } \\
\text { Sesudah }\end{array}$ & $\begin{array}{r}\text { Terapi } \\
\text { dengan }\end{array}$ & 0,09 & 0,30 & \\
$\begin{array}{l}\text { Okupasi } \\
\text { Teknik Kolase }\end{array}$ & & & & \\
\hline
\end{tabular}

Terdapat perbedaan rata-rata mengambil bijian antar individu yang bermakna antara sebelum dan sesudah diberikan intervensi $(\mathrm{P}$ Value $<0,05)$. Sesudah dilakukannya intervensi terjadi peningkatan kemampuan motorik halus dalam mengambil bijian sebesar 0,54.

Tabel 9. Perbedaan Rerata Kemampuan Motorik Halus Anak Autis Dalam Menempel Bijian Pada Gambar Sebelum dan Sesudah Diberikan Terapi Okupasi denganTeknik Kolase di Terapi Anak Mandiri Center Setiabudi Medan Tahun 2015

\begin{tabular}{lrccc}
\hline \multicolumn{2}{l}{$\begin{array}{l}\text { Menempel Bijian Pada } \\
\text { Gambar }\end{array}$} & Mean & SD & P Value \\
\hline $\begin{array}{l}\text { Sebelum } \\
\text { Okupasi }\end{array}$ & $\begin{array}{r}\text { Terapi } \\
\text { dengan }\end{array}$ & 0,90 & 0,30 & \\
$\begin{array}{l}\text { Teknik Kolase } \\
\text { Setelah }\end{array}$ & Terapi & & & 0,002 \\
$\begin{array}{l}\text { Okupasi } \\
\text { Teknik Kolase }\end{array}$ & dengan & 0,27 & 0,46 & \\
\hline
\end{tabular}

Terdapat perbedaan rata-rata menempel bijian antar individu yang bermakna antara sebelum dan sesudah diberikan intervensi $(\mathrm{P}$ Value $<0,05)$. Sesudah dilakukannya intervensi terjadi peningkatan kemampuan motorik halus dalam menempel bijian sebesar 0,63 .

Tabel 10. Perbedaan Rerata Keberhasilan Anak Autis Dalam Mengisi Gambar Sebelum dan Sesudah DiberikanTerapi Okupasi dengan Teknik Kolase di Terapi Anak Mandiri Center Setiabudi Medan Tahun 2015.

\begin{tabular}{lccc}
\hline $\begin{array}{l}\text { Keberhasilan Dalam } \\
\text { Mengisi Gambar }\end{array}$ & Mean & SD & P Value \\
\hline $\begin{array}{l}\text { Sebelum Terapi Okupasi } \\
\begin{array}{l}\text { Dengan Teknik Kolase } \\
\text { Setelah Terapi Okupasi }\end{array}\end{array}$ & 3,63 & 0,80 & \\
\begin{tabular}{l} 
Dengan Teknik Kolase \\
\hline
\end{tabular} & 2,63 & 1,02 & 0,004 \\
\hline
\end{tabular}

Terdapat perbedaan rata-rata Keberhasilan dalam mengisi gambar antar individu yang bermakna antara sebelum dan sesudah diberikan intervensi ( $\mathrm{P}$ Value $<0,05)$. Sesudah dilakukannya intervensi terjadi peningkatan keberhasilan dalam mengisi gambar sebesar 1,00 .

\section{PEMBAHASAN}

Kemampuan motorik halus yang peneliti observasi yaitu : memberi lem pada gambar, mengambil bijian, dan menempel bijian pada gambar dilanjutkan dengan kegiatan mengisi gambar. Keempat kemampuan tersebut menentukan keberhasilan responden dalam mengisi gambar yang disediakan oleh peneliti sebagai lembar instrumen dalam menentukan keberhasilan mengisi gambar sebelum dan sesudah dilakukan terapi okupasi dengan teknik kolase yang dapat dijabarkan di bawah ini :

1. Memberi lem pada gambar

Memberi lem pada gambar adalah suatu usaha yang dilakukan untuk memberikan perekat pada gambar untuk menahan objek yang akan dipadukan pada gambar tersebut. Lem yang digunakan dalam penelitian ini adalah lem fox. Sebelum dilakukan terapi okupasi dengan teknik kolase mayoritas anak autis dapat memberi lem pada gambar dengan bantuan sebanyak 7 anak $(63,6 \%)$ dengan rerata kemampuan 0,60 . Setelah dilakukan terapi okupasi dengan teknik kolase mayoritas anak autis dapat memberi lem pada gambar tanpa bantuan sebanyak 7 anak $(63,6 \%)$ dengan rerata kemampuan 0,50. Sehingga dapat dinyatakan bahwa pelaksanan terapi okupasi dengan teknik kolase dapat memberikan perkembangan motorik halus anak autis dalam memberi lem pada gambar dengan rerata perkembangan 0,10 .

\section{Mengambil bijian}

Mengambil bijian adalah Suatu usaha untuk memindahkan bijian dari satu tempat ketempat lain menggunakan ujung-ujung jari. Biji-bijian yang digunakan dalam penelitian ini adalah biji pohon, beres ketan, kacang 
kedelai, kacang hijau dan kacang mente. Sebelum dilakukan terapi okupasi dengan teknik kolase mayoritas anak autis dapat mengambil bijian dengan bantuan sebanyak 7 anak $(63,6 \%)$ dengan rerata kemampuan 0,63. Setelah dilakukan terapi okupasi dengan teknik kolase mayoritas anak autis dapat mengambil bijian tanpa bantuan sebanyak 10 anak (90,9\%) dengan rerata kemampuan 0,09. Sehingga dapat dinyatakan bahwa pelaksanaan terapi okupasi dengan teknik kolase dapat memberikan perkembangan motorik halus anak autis dalam mengambil bijian dengan rerata perkembangan 0,54 .

3. Menempel bijian pada gambar

Menempel bijian pada gambar adalah Suatu usaha untuk menyatukan atau memadukan bijian pada pada gambar yang disediakan. Sebelum dilakukan terapi okupasi dengan teknik kolase mayoritas anak autis dapat menempel bijian pada gambar dengan bantuan sebanyak 10 anak $(90,9 \%)$ dengan rerata kemampuan 0,90. Setelah dilakukan terapi okupasi dengan teknik kolase mayoritas anak autis dapat menempel bijian tanpa bantuan sebanyak 8 anak $(72,7 \%)$ dengan rerata kemampuan 0,27. Sehingga dapat dinyatakan bahwa pelaksanaan terapi okupasi dengan teknik kolase dapat memberikan perkembangan motorik halus anak autis dalam menempel bijian dengan rerata perkembangan 0,63 .

\section{Mengisi gambar}

Mengisi gambar adalah suatu usaha yang dilakukan untuk memberikan warna pada gambar yang diganti dengan penempelan bijian pada bagian gambar sesuai warna objek. Keberhasilan anak autis dalam mengisi gambar sebelum dilakukan terapi okupasi dengan teknik kolase mayoritas hanya dapat mengisi < 69\% gambar yang disediakan peneliti sebanyak 9 anak $(81,8 \%)$ dengan rerata kemampuan 3,63. Setelah dilakukan terapi okupasi dengan teknik kolase mayoritas keberhasilan anak autis dapat mengisi 70\%-74\% gambar sebanyak 5 anak (45,5\%) dengan rerata kemampuan 2,63. Sehingga dapat dinyatakan bahwa adanya pengaruh pemberian terapi okupasi dengan teknik kolase pada anak autis dalam mengisi gambar yang disediakan oleh peneliti dengan nilai rerata perkembangan keberhasilan dalam mengisi gambar 1,00 .

\section{SIMPULAN}

Dari hasil penelitian yang dilakukan mengenai pengaruh terapi okupasi dengan teknik kolase terhadap perkembangan motorik halus anak autis di Terapi Anak Mandiri Center Setiabudi Medan Tahun 2015 maka didapat kesimpulan sebagai berikut : Adanya peningkatan perkembangan motorik halus anak autis dalam memberi lem pada gambar setelah dilakukan terapi okupasi dengan teknik kolase dengan rerata perkembangan sebesar 0,10 . Adanya peningkatan perkembangan motorik halus anak autis dalam mengambil bijian setelah dilakukan terapi okupasi dengan teknik kolase dengan rerata perkembangan sebesar 0,54 . Adanya peningkatan perkembangan motorik halus anak autis dalam menempel bijian setelah dilakukan terapi okupasi dengan teknik kolase dengan rerata perkembangan sebesar 0,63. Adanya peningkatan keberhasilan dalam mengisi gambar setelah dilakukan terapi okupasi dengan teknik kolase dengan rerata peningkatan sebesar 1,00. Hasil uji statistik t-test menunjukkan bahwa perkembangan motorik halus sebelum dan sesudah intervensi berbeda secara signifikan yaitu nilai $\mathrm{P}$ value $<0,05$ yang artinya bahwa Ho ditolak dan Ha diterima. Sehingga dapat dinyatakan bahwa pelaksanaan terapi okupasi dengan teknik kolase dapat memberikan pengaruh terhadap perkembangan motorik halus anak autis.

\section{SARAN}

Kepada para profesional kesehatan untuk memberikan support sistem kepada orangtua yang mempunyai anak Autis agar patuh dalam menjalani terapi okupasi dengan teknik Kolase sesuai yang diajarkan terapis Disarankan kepada terapis untuk menerapkan terapi okupasi dengan teknik kolase dengan menggunakan benda-benda yang bervariasi untuk pengembangan kemampuan motorik halus anak berkebutuhan khusus terutama anak autis. Disarankan terapi okupasi dengan teknik kolase dapat digunakan sebagai referensi peneliti lain dan dapat dikembangkan agar lebih bervariasi dalam pengembangan kemampuan motorik halus anak autis.

\section{DAFTAR PUSTAKA}

Adriana, Dian. 2013. Tumbuh kembang dan terapi bermain pada anak. Jakarta : Salemba Medika

Depkes. 2006. Pedoman Pelaksanaan Stimulasi, Deteksi dan Intervensi Dini Tumbuh Kembang Anak di Tingkat Pelayanan Kesehatan Dasar.

Hidayat, A. Azis Alimul. 2013. Metode Penelitian Keperawatan dan Teknik Analisis Data. Jakarta : Salemba Medika.

Hasdianah. 2013. Autis Pada Anak Pencegahan, Perawatan, dan Pengobatan.Yogyakarta : Nuha Medika.

Huzaemah. 2010. Kenali Autis Sejak Dini. Jakarta : Pustaka Populer Obor.

Kumalasari, Effi. 2005. Peningkatan perkembangan Motorik Halus Anak Melalui Kegiatan Kolase Dari Bahan Bekas di Taman Kanak-Kanak Aisyyah Simpang IV Agam. Jurnal Pesona PAUD, (online), Vol 1, No. 1, (http :// www.potal garuda. Org, diakses 9 November 2013).

Muharrar, Syakir dan Sri, Verayanti. 2013. Kolase, Montase, Mozaik. Semarang : Esensi.

Nurjatmika, Yusep. 2012. Ragam Aktivitas Harian Untuk TK. Yogyakarta : Diva Press

Sukardi, Evan S. Dan Hajar, Pamandhi. 2008. Seni Keterampilan Anak. Jakarta : Universitas Terbuka.

Sunu, Christoper. 2012. Panduan Pemecahan Masalah Autisme Unlocking Autism. Yogyakarta : Lintang terbit. 